\title{
THE LUBRICATION OF ANIMAL JOINTS IN RELATION TO SURGICAL RECONSTRUCTION BY ARTHROPLASTY*
}

BY

\author{
JOHN CHARNLEY \\ Manchester Royal Infirmary and The Centre for Hip Surgery, Wrightington Hospital, near Wigan, Lancs
}

The accepted theory of joint lubrication is that of MacConaill (1932), who assembled arguments to show that it was an example of hydrodynamic or full-film lubrication.

The principal argument in applying the hydrodynamic theory to animal joints was the anatomical fact that in joints the curvatures of articulating surfaces are not completely congruous throughout their whole arc of movement. It was observed by Walmsley $(1917,1928)$ that the surfaces of the knee and hip are exactly congruous only in the position of full extension, which is the position of the motionless erect stance, but that in the arc employed for walking or running the convex surface has a slightly smaller radius than the concave surface. This presented to MacConaill's mind the existence of wedge-shaped spaces, occupied by wedge-shaped films of synovial fluid; it is the essence of the hydrodynamic theory that fluid pressure is generated in a wedge of lubricant as a result of the motion of the surfaces and that this pressure supports the load and keeps the sliding surfaces separated on a cushion of lubricant (Fig. 1).

Even before examining the problem experimentally in animal joints, there are theoretical criticisms which make the hydrodynamic theory unlikely. Firstly, the articular cartilage, which is present as a layer about $\frac{1}{8}$ in. thick over the sliding surfaces of the joint, is very resilient, being easily indented by pressure of the thumb-nail. An ankle-joint of an adult male has a projected surface area of less than 2 sq. in., so that a man weighing 12 st. carrying a 1-cwt. load on his shoulders will expose an anklejoint to pressures of about $150 \mathrm{lb}$. per sq. in. There can be little doubt that these resilient surfaces are intimately applied to each other over the whole area especially when carrying loads.

* Based on a paper given at a joint meeting of the Heberden Society and the British Association of Physical Medicine on July 25, 1959.
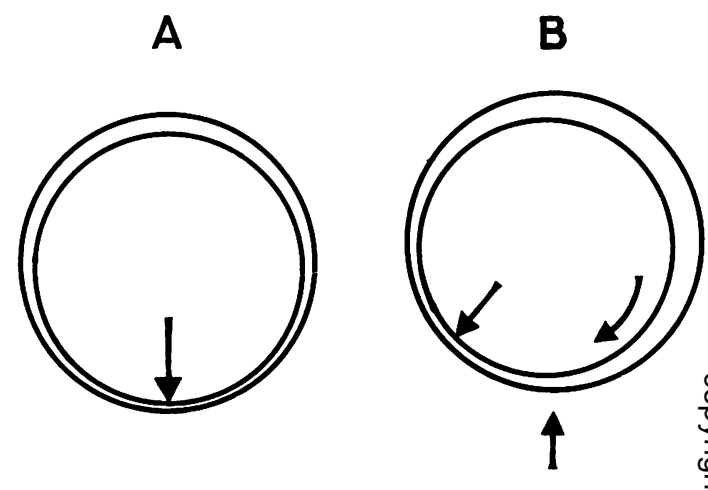

Fig. 1A.-Shaft in a bearing before rotation starts. Arrow indicates point of contact between shaft and bearing from which lubricant is expelled.

Fig. 1B. - Shaft in rotation. Lubricant is carried into convergent wedge to build up cushion of lubricant below it to support load on shaft. Shaft is displaced so that the narrowest part of the film of lubricant is no longer vertically below it.

Secondly, there is the well-known fact that hydrodynamic lubrication is not suited to conditions where the motion is reciprocating, because no sooner has a fluid wedge been established for motion in one direction than it is destroyed as motion starts in the other. Thirdly, hydrodynamic lubrication is not easy to achieve with slow-moving surfaces under heavy loads.

In hydrodynamic or full-film lubrication, the nature of the substances composing the sliding surfaces and the nature of the fluid used as a lubricant, are theoretically unimportant; the essentials are the geometry of the surfaces and the viscosity of the fluid. In this type of lubrication it is not necessary for the fluid to possess the property of "oiliness".

The form of lubrication which is the complete opposite of hydrodynamic lubrication is that known 
as "boundary" lubrication (Bowden and Tabor, 1956). It is the antithesis of full-film lubrication in that the quality of the substances comprising the sliding surfaces and the quality of the fluid used as a lubricant are the essential features; the shape of the surfaces and viscosity of the fluid are unimportant. An example of the lack of correlation to viscosity is the fact that a watery solution of oleic acid is a better lubricant for glass sliding on glass than pure glycerine, though the latter is many times more viscous. In this type of lubrication the property of "oiliness" is fundamental, but, which is more important, it is not the "oiliness" of the lubricant itself but the property of oiliness when applied to the sliding surface. Thus methylated spirit has no more suggestion of oiliness than water when tested between the fingers, but for rubber it is a better lubricant than water. This illustrates the important fact that in boundary lubrication a lubricant has an affinity for the surface it lubricates, so that when motion takes place between two such lubricated surfaces it takes place between monomolecular films of lubricant chemically adherent to the underlying surface (Fig. 2). It is obvious that monomolecular films which are bound to the sliding surfaces are less likely to rupture under heavy loads than films of a lubricant which is inert towards the substance of the surface, because the integrity of such a film depends only on the intermolecular attraction in the fluid itself, and the intermolecular attraction of a fluid is obviously less than that of a solid. The molecules of a fluid which are bound to the surface of a solid lose the physical properties of a liquid. In the case of mineral oils, which have no chemical affinity for metals, the addition of small quantities of fatty acids greatly enhances their lubricating properties; this is explained by soaps being formed between the fatty acids and the metal, with the result that motion takes place between two layers of molecules all with their $-\mathrm{COOH}$ groups attached to the metal surface and the fatty chain projecting like the bristles of a brush.

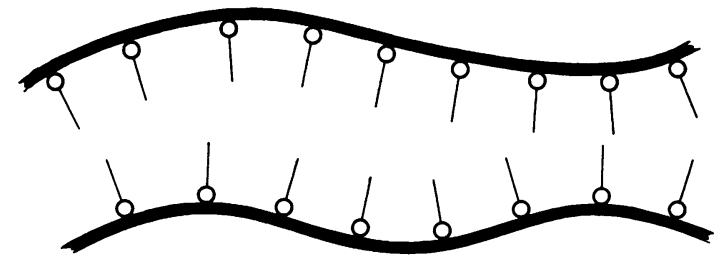

Fig. 2.-Boundary Lubrication. The irregular rubbing surfaces are separated by monomolecular films of lubricant bound to these surfaces by physico-chemical adhesion. The low-friction phenomenon is thus a function of low molecular attraction between the free ends of the adherent molecules of boundary lubricant.
This type of lubrication is exactly suited to the condition to which hydrodynamic (full-film) lubrication is not, that is, slow reciprocating motion under heavy loads. On these theoretical grounds it would seem that the conditions of joint lubrication are more akin to boundary lubrication than to full-film lubrication.

It is here that the greatest difficulty is encountered in lubrication theory, because in practice it is rare to find a pure example of either full-film or boundary lubrication and the commonest form of lubrication is a mixture of the two: "quasi-hydrodynamic" lubrication. Thus, in a bearing designed for true hydrodynamic lubrication, a full-film will be established only when the bearing is running at its calculated speed, while boundary conditions will be present when it is stationary. Similarly, in boundary lubrication, boundary conditions will exist only at the summits of elevated surface irregularities while in the intervening depressions hydrodynamic conditions are possible. With increasing speed the contribution of hydrodynamic lubrication will increase.

\section{Coefficient of Friction of Articular Cartilage}

The coefficient of friction, $\mu$, is a simple ratio between the force necessary to make a body slide on a surface and the force pressing the body against the surface. A coefficient of friction of 0.1 means that a body will slide on a horizontal surface if a force equal to one-tenth of its weight is applied to it.

In the engineering laboratory it is easy to measure a coefficient of friction because one body can be made into a plane surface and the other body made to slide on it through the medium of a device for measuring force, such as a spring-balance. Unfortunately, articular cartilage cannot be fashioned into a plane surface and therefore estimation of its coefficient of friction offers special technical difficulties. The only record of this measurement to have been published is that of Jones (1934) who obtained the very low figure of $0 \cdot 02$. This figure was obtained by using a large joint from an ox, and although the design of the experiment showed great mechanical ingenuity, it was open to the theoretical objection that the ligaments of the joint were retained in their intact state in order to form an axis of motion to locate the rubbing surfaces on each other; the resistance to movement offered by these ligaments is an unknown quantity and theoretically might raise the recorded coefficient above its true value.

It was decided to attempt to make this measurement by sliding the femoral condyles of a freshly 
amputated human knee-joint against the corresponding articular surface of the tibia after the ligaments and all extraneous tissues had been removed. To locate the rubbing surfaces against each other in the absence of ligaments, it was decided to use a ball-race, because this has a coefficient of friction which is constant for the conditions of the experiment and which may be estimated at about $0 \cdot 001$.

The mechanical difficulty is that the articular surfaces of the tibia are not flat and, under the influence of a load applied to the joint, there is a tendency for movement in one direction to be "uphill" and in the other direction "downhill". By restricting the movement between the rubbing surfaces to less than $3 \mathrm{~mm}$., this difficulty was minimized. The tendency to spontaneous movement downhill under load was counteracted by using small balance weights to hold the slippery 끅 condyles in equilibrium on the downhill slope. $\stackrel{\Phi}{\odot}$ The friction force was applied with the system in $\overline{3}$ equilibrium and the mean was taken of the forces 0 needed to slide the surface first uphill and then downhill.

APPARATUS.-The apparatus used in this experiment $\frac{+}{\sigma}$ is illustrated diagrammatically in Fig. 3. The condyles $\frac{\bar{C}}{\sigma}$ of the femur $A$ were attached rigidly to a horizontal $\overline{\bar{\omega}}$ beam B pivoted on roller bearings. Rocking of the beam $\underset{\mathbb{\Phi}}{\vec{T}}$ on these bearings thus caused the articular surface of the $\varrho$ condyles to move backward and forward on the arc of a circle of radius $R$. The arc was restricted to one $\vec{P}$ or two degrees by suitable stops $\mathrm{C}$. The roller bearings were located by two levers $D$, which permitted the $\overrightarrow{\vec{\omega}}$ femoral condyles to rise and fall; by this means the femoral surface could be lowered on to the tibial surface which was placed below it on a suitable platform. The으 load W ranging from $6 \mathrm{lb}$. to approximately $600 \mathrm{lb}, \overrightarrow{0}$

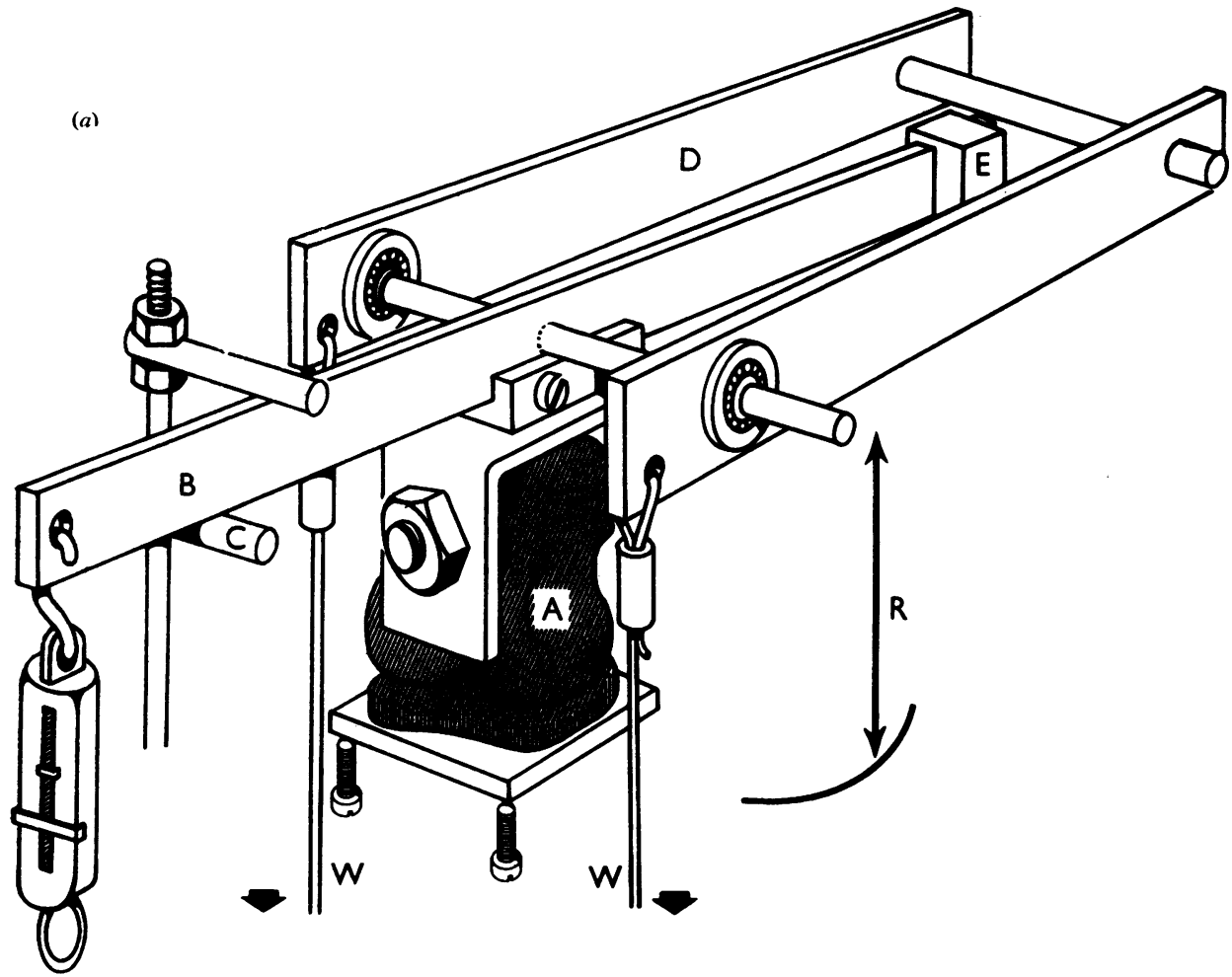

Fig. 3.-Arrangement to measure coefficient of friction in a cadaveric specimen of a human knee joint. (Courtesy of Inst. mech. Eng., Proceedings of Symposium on Biomechanics, April 17, 1959, Fig. 22.)

(a) Arrangement

$$
\begin{array}{lllll}
\text { A } & \text { Condyles } & & \text { D } & \text { Levers } \\
\text { B } & \text { Horizontal beam } & \text { E } & \text { Balance weights } \\
\text { C } & \text { Stops } & \text { W } & \text { Load } \\
& & \text { R } & \text { Radius of circle }
\end{array}
$$

(b)
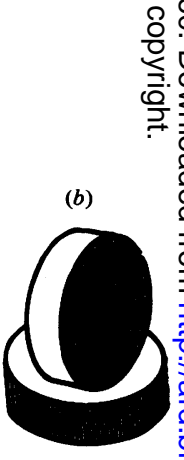

$$
\text { . }
$$


was applied to the rocking axis of the beam through Bowden cables by a system of levers. When the load was applied to the condyles the tendency for the beam to move spontaneously was counteracted, first by adjusting the position of the tibial surface under the femoral condyles, and secondly by applying small balanceweights $E$ to one end of the beam to bring it into equilibrium. The position of equilibrium was adjusted between the stops $\mathrm{C}$ which restricted the arc of movement during the test. The force necessary to start the beam moving first in one direction and then in the other was then measured. To do this was easy when the joint was under heavy load; a spring-balance with a pointer which held a maximum reading was used to apply the force to move the beam first up and then down and to record the force at the moment when sliding started. When the joint was under light loading, the force needed to rock the beam was so low that a time factor became evident in relation to the rate at which the force was applied, which suggested a phenomenon of viscous flow. To make measurements in these circumstances a loop of chain was used with links of known weight, so that the force could be applied with a uniform rate of loading and repeated in opposite directions until a fair estimate could be made.

The coefficients obtained from seven experiments ranged from a minimum of 0.005 to a maximum of 0.023 (average 0.013 ).

In this series of experiments the most interesting feature was that no difference in the coefficient was observed when all visible traces of synovial fluid were removed by wiping the articular surfaces with a dry cloth or when the rubbing surfaces were freely lubricated with an excess of synovial fluid deliberately applied to the site of movement.

How extraordinarily low is this coefficient of friction 0.01 can be appreciated only if it is realized that it is approximately three times better than the coefficient for ice sliding on ice, which is approximately 0.03 , and between ten and twenty times better than that for a polished steel surface moving on a lubricated brass bearing, which is within the range of $0 \cdot 1$ to $0 \cdot 2$.

The extraordinary fact of this very low coefficient of friction in an animal joint does not seem to have been observed by biologists. A coefficient of 0.01 means that a load of $100 \mathrm{lb}$. (the weight of a small adult) could be made to slide by applying a force of only $1 \mathrm{lb}$. If articular cartilage were to be no more slippery than a plain engine-bearing, the same load would need a force of 10-20 lb. to make it slide. If we consider that, in the lower extremity of a human being, four sliding surfaces are used simultaneously in each limb when walking or running (hip, knee, knee-cap, and ankle) we see that for an adult weighing $100 \mathrm{lb}$., $4 \mathrm{lb}$. would be needed to move all these joints, but, if lubricated metal bearings were substituted for the articular cartilage, a total force of 40-80 lb. would be needed to overcome frictional resistance. The remarkable way in which Nature has solved this friction problem will be appreciated when it is realized that to equal it an engineer would have to discard plain bearings and employ a so-called "frictionless" bearing where the rolling mechanism of a ball-race takes the place of sliding friction.

\section{Pendulum Experiment}

The most interesting experiment in the relatively small literature which exists on the mechanical aspects of joint lubrication is that described by Jones (1936), in which he used a pendulum method for measuring the coefficient of friction as described by Stanton (1923). By this method, a lubricated bearing is made the pivot of a pendulum. The coefficient of friction of the bearing can be calculated by comparing the rate of decay of amplitude as the pendulum swings on the test bearing with the rate of decay when the bearing is replaced by a frictionless knife-edge. This method presents a specially attractive feature, in that it is very easy to calculate the coefficient of friction at different speeds of sliding, the linear velocity at the rubbing surface being high when the amplitude is large and vice versa. It has been recognized since the early work of Coulomb (1866)* that within fairly wide limits the coefficient of friction is unaffected by the speed of sliding, and therefore that, if boundary conditions were to exist in the bearing at the pivot of the pendulum, the coefficient of friction should remain the same at all amplitudes of swing; if hydrodynamic conditions were to exist, the coefficient of friction should diminish with a diminishing amplitude of swing because the viscosity of fluids decreases with velocity.

To apply this theory to a joint, Jones used an intact finger joint amputated from the cadaver and by suitable means made it the pivot of a pendulum. He found that the coefficient of friction diminished as the amplitude of the swing diminished, and he therefore decided that the conditions of normal joint lubrication were hydrodynamic and not boundary. This experiment has been widely quoted in the literature to support the hydrodynamic theory, but two defects in the experiment present themselves:

(1) The surfaces of an interphalangeal joint are imperfectly congruous, and therefore to locate one surface on the other it is necessary to retain intact the ligaments of the joint. At large amplitudes the friction between the articular surfaces might appear

\footnotetext{
* See Bowden and Tabor (1956).
} 
greater than the true value by work done in moving the ligaments and capsule; at low amplitudes the contribution of resistance from the capsule and ligaments would be less and the coefficient of friction would therefore appear lower at the small amplitudes.

(2) The lack of congruity in the joint would permit the articular surfaces to change from a true sliding motion at large amplitudes to a rolling motion at low amplitudes. At low amplitudes a rolling motion would present less resistance to movement than the sliding motion which would be superadded at large amplitudes.

Both these objections could explain a fall in the observed coefficient of friction with reduced amplitude of the pendulum without invoking viscosity and the theory of hydrodynamic lubrication.

To repeat this experiment it was necessary to find an animal joint possessing surfaces of a high degree of congruity in order to provide positive location for the rotation of one surface on the other in the absence of ligaments. The human ankle-joint is very suitable for this purpose because the cylindrical convexity of the upper surface of the talus is received into a deep concavity in the tibial surface and a stable location is maintained over quite large angles of movement.

A pendulum 45 in. in length carrying a bob weighing $30 \mathrm{lb}$. was attached to a cadaveric ankle-joint, as illustrated in Fig. 4. The talus was carried in the corresponding saddle-shaped articular surface of the tibia, which was mounted on a platform with an arrangement for tilting so that the actual bearing surface could be rendered horizontal. An arrangement was provided to elevate the pendulum and unload the surfaces under test in the interval between tests.

The amplitude of swing was measured cinematographically with a 16 frame/s. cine-camera photographing the movement of a pointer passing in front of a transparent illuminated scale. The maximum angular displacement of the bob from its position of rest was not more than $5^{\circ}$ and the pendulum was set swinging by burning a string holding it at the starting position of deflection.

To find the rate of decay of amplitude due to airdamping, knife edges were substituted for the test specimen $\mathrm{E}$.

The method of calculating the coefficient of friction has been reported in detail by Edwards (1959).

Two experiments of this type, using different specimens, were carried out, giving the following value for $\mu$ :

Experiment $2 / 11 \quad \ldots \quad \ldots \quad \mu=0.024$

Experiment $2 / 12 \quad . . \quad \ldots \quad \mu=0.014$

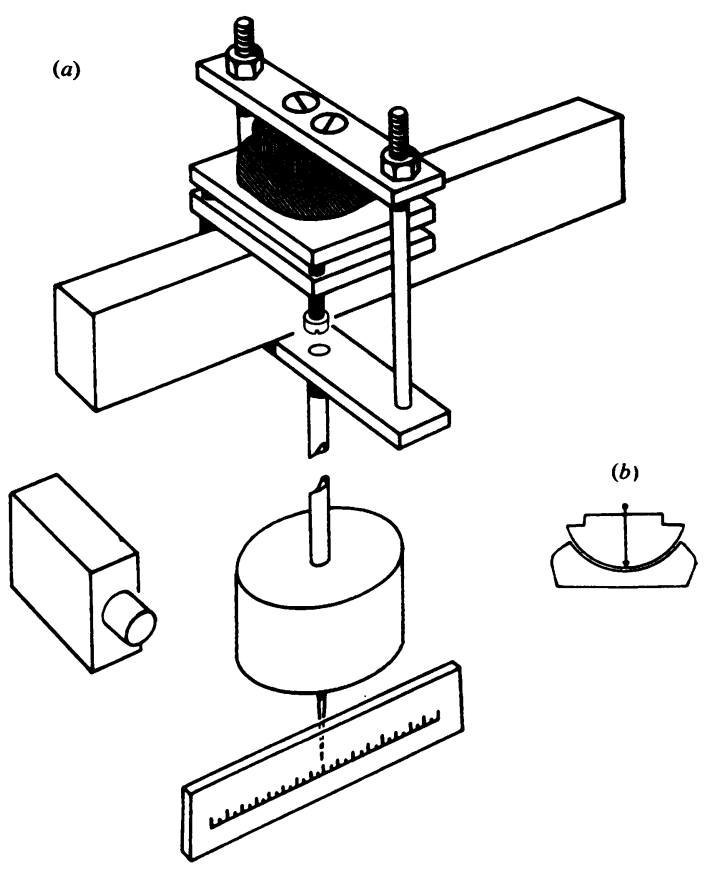

Fig. 4.-Stanton's pendulum arranged for the measurement of friction $\vec{\theta}$ in a human ankle-joint. (Courtesy of Inst. mech. Eng., Proceeds ings of Symposium on Biomechanics, April 17, 1959, Fig. 23.)

(a) Arrangement.

(b) Shape of rubbing surfaces indicated diagrammatically. this arrangement the joint elements are upside down in relation to the erect position of the human body.

For comparison purposes, and for preliminary $\frac{\mathscr{Q}}{\mathbb{Q}}$ tests of the apparatus, the value of $\mu$ was obtained $\underset{\vec{F}}{\vec{F}}$ for metal surfaces lubricated with oil which had the same dimensions as the cylindrical surfaces of the human ankle-joint:

Experiment $2 / 3$

Brass/stainless steel/oil $\quad . \quad \ldots \quad \mu=0.228 \stackrel{\varrho}{\frac{0}{2}}$

Experiment 3/5

Brass/P.T.F.E. (Polytetrafluorethylene) $\mu=0.049 \stackrel{3}{3}$

These latter figures are consistent with reported $\delta$ values obtained by routine methods.

When plotted as a graph of amplitude against the 옹 number of the pendulum excursions (Fig. 5, oppo- $>$ site), it is seen that the decay of amplitude in the case of articular cartilage is linear, thus showing that the $\bar{N}$ frictional resistance is the same at all speeds of $\sigma$ sliding of the cartilage surfaces. This confirms $N$ the suspicion that the non-linear decrease in ampli- N tude reported by Jones must have been due to the errors in design already suggested.

These experiments thus support the idea that the $\frac{0}{\Phi}$ predominant mechanism in joint lubrication is a $\stackrel{\mathcal{D}}{?}$ boundary phenomenon and that any quasi-hydro- 0 dynamic lubrication which theoretically might 


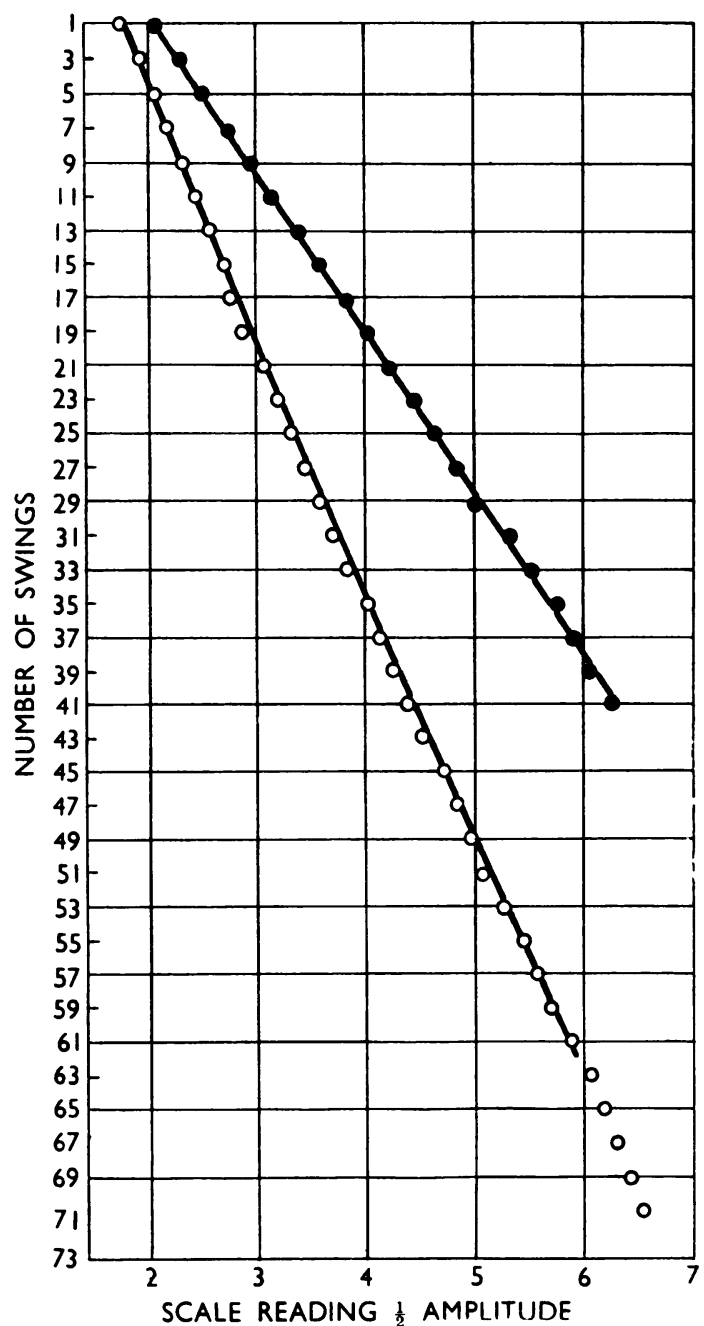

Fig. 5.-Decrease in swing plotted graphically showing, by the linear disposition of the parts, the constancy of the coefficient of friction with decreasing velocity of sliding, which is incompatible with the hydrodynamic theory of lubrication. (Courtesy of Inst. mech. Eng., Proceedings of Symposium on Biomechanics, April 17, 1959, Fig. 24.)

develop as the speed rises is not present in the range of speeds covered by this experiment.

\section{Synovial Fluid as a Lubricant}

Another possibility which has to be considered as an explanation of the extraordinary low coefficient of friction in animal joints is that synovial fluid may possess properties as a lubricant unknown in engineering. Two pieces of experimental evidence suggesting this have been adduced by Ogston and Stanier (1953).
The first piece of evidence is that films of synovial fluid have a remarkable tenacity and resistance to rupture. By compressing a film of synovial fluid between a plane surface and a convex lens they were able to show from the measurement of Newton's rings that films of 20-50 $\mathrm{m} \mu$ thickness would resist pressure of $10-100 \mathrm{~kg} . / \mathrm{sq} . \mathrm{cm}$. They attributed this behaviour to the molecular structure of the complex mucopolysaccharide, hyaluronic acid, which is responsible for the viscosity of synovial fluid: "the voluminous, randomly coiled particles may be thought of as being trapped and squeezed like a sponge, between the two surfaces".

The second piece of evidence is the finding that, as regards its viscosity, synovial fluid behaves in a non-Newtonian manner. To quote Ogston and Stanier: "The viscosity is very high at the lowest rates of shear, so that the joint is enabled to support a high load even at a low rate of movement. At higher rates of movement the viscosity falls, so that the drag of the joint is relatively lowered: the load which it will bear is not reduced, because the greater rate of movement more than offsets the fall in viscosity. A normal (Newtonian) fluid would not give these advantages."

It is evident that Ogston and Stanier are making the assumption that, at the higher rates of shear, the joint is lubricated by a fluid of low viscosity under hydrodynamic conditions, the existence of which the present investigation denies.

The curves (Fig. 6, overleaf) reproduced from Ogston and Stanier (1953) are those of the relative viscosity of synovial fluid in different concentrations against velocity gradient. Tanner (1959) has shown that the velocity gradient in the human hip joint walking at 4 m.p.h., calculated for a film thickness of $1 / 1,000$ in., will lie at that part of the graph where synovial fluid is acting as a thin Newtonian liquid, in the region corresponding to a shear rate of $2,500 \mathrm{~s}^{-1}$. Thus, while it is possible that the property of synovial fluid in providing strong films may have some action in stationary joints under load, there are no grounds for believing that this explains the low friction of a joint in motion.

The protagonists of synovial fluid as a special lubricant subserving the theory of hydrodynamic lubrication appear to dismiss as unimportant the fact that Ropes, Robertson, Rossmeisl, Peabody, and Bauer (1947) found no lubricating properties when synovial fluid was tested dynamically in an artificial joint made of Perspex. This fact seemed so important that it was decided to re-examine this aspect of the problem, and for this purpose an artificial joint was constructed, having the basic shape and average dimensions of an adult ankle- 

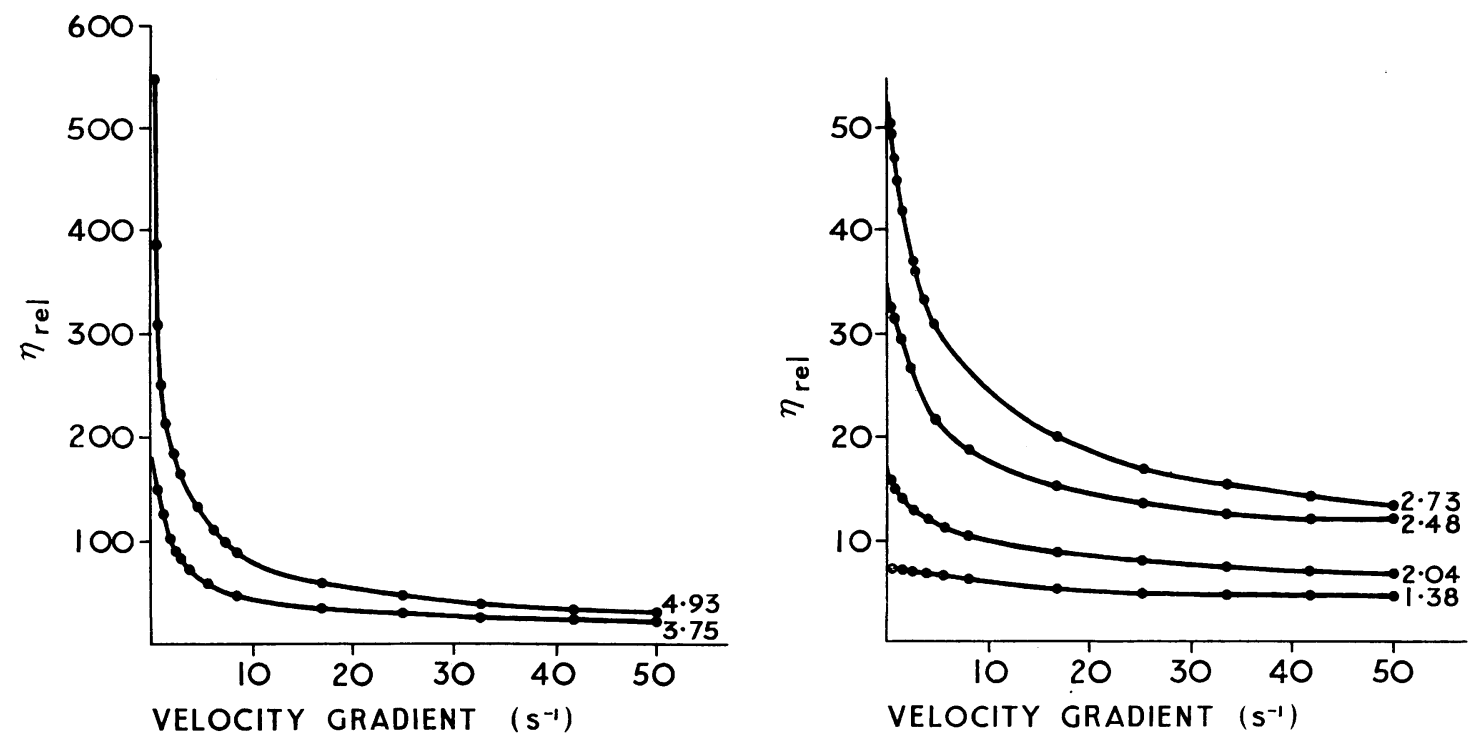

Fig. 6. - Rate of shear of ox synovial fluid at different concentrations, showing non-Newtonian behaviour at velocity gradients under s-1 (Inst. mech. Eng., Proceedings of Symposium on Biomechanics, April 17, 1959, Fig. 25; J. Physiol. (1953), 119, 244, Fig. 6, Ogston and Stanier.)

joint. The results of these experiments showed that synovial fluid was unable to establish and maintain a full film by the mechanism of hydrodynamic lubrication. Synovial fluid was only slightly superior to thin paraffin oil in its ability to maintain a film; after a few swings of the pendulum all the fluid was expelled and the metallic surfaces came into contact and were in danger of becoming heavily scored.

It was interesting to observe that even with the thickest lubricating oils this artificial ankle-joint with dimensions equal to that of a human subject could not establish permanently a full film under a load less than half the weight of an adult at a rate corresponding to walking speed.

It was particularly interesting to note that the artificial bearing used for this experiment was lapped to a fit of $1 / 10,000$ in.: my engineering colleagues insisted on this degree of accuracy in order to give every facility for the establishment of hydrodynamic conditions. The surgical concept of the angle of the fluid wedge nesessary to establish hydrodynamic lubrication is quite erroneous and the gross lack of congruity according to engincering standards encountered in an animal joint is a strong argument against hydrodynamic lubrication and in favour of boundary conditions at the point of contact.

\section{The Synovial Sponge}

From these considerations it is proposcd that there are no grounds for believing that joint lubrica- tion is an example of hydrodynamic or full-film lubrication. It has yet to be decided whether joint lubrication is pure boundary lubrication or boundary lubrication with a significant contribution of quass hydrodynamic lubrication from the free synoviat fluid present in the joint cavity. It has alread产 been shown that the coefficient of friction of articus lar cartilage is not significantly altered when the sliding surfaces are wiped free of visible wetting by synovial fluid.

Articular cartilage, which covers with a thin layer the ends of the bones forming a joint, is not a rigid structure like a journal bearing; it is a flexible, almost gelatinous, substance, which shares with synovial fluid the fact that in its composition there is more water than solid substance. If, after wiping the surfaces of the articular cartilage free of any loose synovial fluid, a fresh joint is compressed under a heavy load, a fluid apparently identical with synovial fluid will be expressed from the joint 응 surfaces. It thus becomes impossible to decide $\supset$ whether the smear of synovial fluid which may be present on the joint surfaces derives from the joint $\bar{N}$ cavity and is laid on the sliding surfaces, or whether $\sigma$ it has been generated by the sliding surfaces them- $N$ selves.

Ekholm and Norbäck (1951) have shown that, after a period of exercise, the articular cartilage of a joint is detectably thicker than in the resting state $\underset{D}{\mathbb{2}}$ and that this increase in thickness is due to distension $\stackrel{0}{?}$ of the chondrocytes.

These facts thus give some substance to the ten- 
tative idea that the free synovial fluid present under a joint may be a by-product of the rubbing surfaces and not, as has generally been assumed, an essential fluid required for the purpose of moistening the rubbing surfaces of the joint.

This idea of articular cartilage as a sponge containing in its interstices the same fluid which is free in the cavity of the joint as synovial fluid can be used to criticize the experiment advanced by Barnett (1956) in favour of the hydrodynamic theory of joint lubrication. In this experiment the knee joints of freshly-killed rabbits were exercised through a normal range of movement by an electrically-driven mechanism. The joint on one side was retained as a control and on the experimental side the joint was injected with an enzyme, hyaluronidase, which destroys the essential molecule of hyaluronic acid which is responsible for the viscosity of synovial fluid. At the end of the experiment it was found that the joint in which the viscous properties of synovial fluid had been destroyed had suffered serious mechanical damage to the sliding surfaces. From this it was concluded that joint lubrication must be hydrodynamic. The concept of articular cartilage as a sponge, sharing the properties of synovial fluid renders this experiment untenable. The enzyme hyaluronidase would destroy the articular surfaces just as it did the free synovial fluid. This experiment would have been valid if the experimental joint had been continuously irrigated with a harmless fluid such as isotonic saline; if the joint had then deteriorated this would have suggested the importance of free synovial fluid on the surface of the articulating surfaces.

\section{Surgical Materials in Arthroplasty}

There have been many mechanical studies of arthroplasties, especially in regard to the reconstruction of the hip-joint, but the frictional properties of the substances employed do not seem to have received attention. It is evident that it is not enough to study the static loads transmitted from a prosthetic replacement of the head of the femur to the stump of the neck of the femur if, as a result of frictional resistance to rotation of the prosthetic head in the acetabulum, the bond between the prosthesis and the bone is exposed to powerful torque forces tending to twist it loose. If it were possible to present a prosthetic femoral head with an acetabulum as slippery as a normal articulation, the bond between the prosthesis and the neck of the femur would be spared from twisting strains and the design of the anchorage of the prosthesis to cope with major forces in only one direction would be enormously simplified.
Using the general techniques previously outlined, experiments have been carried out to compare the coefficient of friction of a normal joint with the friction encountered between bone and the materials commonly used in arthroplasty, such as stainless steel, cobalt-chromium alloy, and polymethylmethacrylate (Perspex). Even when lubricated with ox synovial fluid, the coefficient of friction of bare bone against these artificial substances was found to be very adverse, being in the region of 0.4 . It was quite easy, using the pendulum technique, to generate an audible "squeak" between bone and perspex, moistened with ox synovial fluid. This reproduced the squeak which is sometimes heard when a Judet prosthesis is placed in an eburnated, osteo-arthritic, acetabulum.

A feature of considerable interest was that, though bone moistened with synovial fluid showed very high frictional resistance against steel or Perspex, normal articular cartilage retained its remarkable low-friction property when tested against steel or Perspex. This suggested that the good results of prosthetic replacement of the femoral head, when done for fresh fractures of the femur, might be explained by the slipperiness of the cartilage lining the acetabulum, whereas the results when a prosthesis is used for osteo-arthritis of the hip are generally mediocre.

It is thus fairly obvious that the simple idea of designing an arthroplasty in which a polished metal or plastic sphere replaces the head of the femur and depends for lubrication on the hydrodynamic theory, using what synovial fluid may be available, may not function as well as if the acetabulum is lined with some substance, such as articular cartilage, which is intrinsically slippery. In searching for a suitable slippery substance (i.e. with low boundary friction irrespective of fluids on the surface), the substance polytetrafluorethylene (p.t.f.e.) was found to have properties rendering it highly suitable for developing in the design of an arthroplasty. Used against itself p.t.f.e. has a coefficient of friction of about 0.04 and against steel the value is very much the same. From the point of view of chemistry, it is an exceptionally inert plastic and eminently suitable for implantation into the body, and this has been tested by biological assay. The main disadvantage is that it has limited physical strength and has to be used in design as though it were a dense wax.

This material has been used in arthroplasty of the hip at the Centre for Hip Surgery at Wrightington, and at the Manchester Royal Infirmary, for nearly 3 years and, though the prototype designs have been superseded by recent improvements as a result of 
further experience, the whole course of the investigation, covering some sixty operations, confirms the value of the basic idea. Using a prosthetic replacement of the femoral head articulating with a low-friction lining of p.t.f.e. for the acetabulum (Fig. 7), enough experience has been acquired to enable the following claims to be made for the procedure:

(1) Absolute relief from pain.

(2) Excellent freedom of motion without spasm.

(3) Final range of motion dependent solely on the range before the operation.

(4) Striking absence of new bone formation without loss of the range of motion initially obtained by the operation.

It is as yet too early to make any pronouncement on the final average ability for full weight-bearing without the assistance of sticks. Patients have so far been selected from the category of hopelessly disabled, and full activity has frequently been limited by disease in other joints. In this respect the operation has been of real value to patients with rheumatoid arthritis to whom freedom from pain and joint mobility has been a great boon, even if permanent dependence on crutches or sticks still has

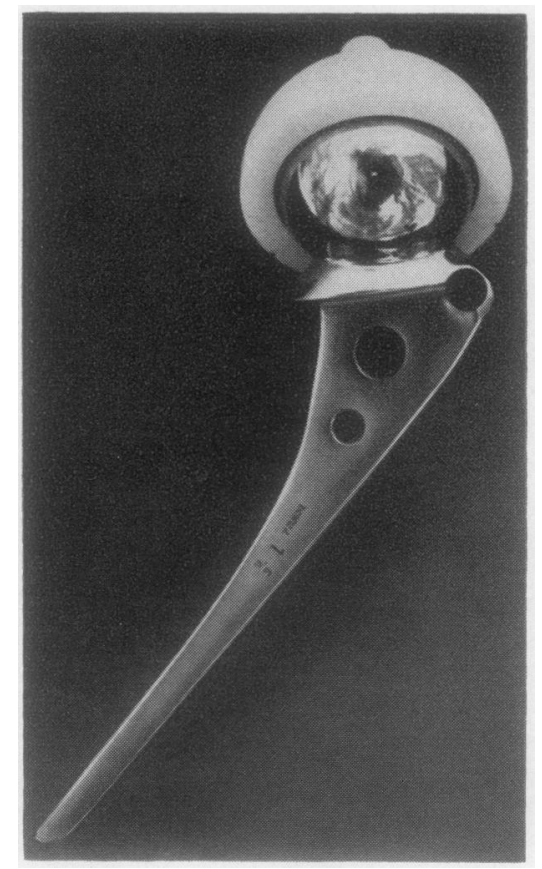

Fig. 7.-Stainless steel fenoral head prosthesis (Moore type) mated with socket of p.t.f.e. used to line the arthritic acetabulum. This is the combination which it is considered can be developed in the treatment of rheumatoid arthritis to give results superior to those obtained by any of the routine methods of hip arthroplasty previously available. to be accepted. We have no doubt of the great value of this procedure in patients with rheumatoid arthritis, even when extensive osteoporosis is present, and the reservations at the moment concern its suitability for osteo-arthritis of the hip in those robust patients for whom alternative, well-tried, methods are still available albeit with the frequent penalty of stiffening, or partial stiffening, the hip.

\section{Summary}

This paper is a critical review of published work on the nature of lubrication in animal joints. $\vec{\circ}$ Certain experiments which have been accepted in $\overrightarrow{\vec{J}}$ support of the theory of hydrodynamic lubrication $\omega_{\overparen{N}}$ have been repeated to show that the lubrication of animal joints is almost certainly a boundary pheno- ? menon. It is emphasized that the coefficient of $\overrightarrow{0}$ friction in animal joints reaches an astonishingly $\rightarrow$ low figure and surpasses in slipperiness any com- $\overrightarrow{0}$ bination of sliding surfaces known to engineering 음 science. It is deduced that attempts to reconstruct $\rightarrow$ artificial joints on the hydrodynamic theory of $\bar{z}$ lubrication are doomed to failure.

\section{REFERENCES}

Barnett, C. H. (1956). J. Bone Jt Surg., 38B, 567.

Bowden, F. P., and Tabor, D. (1956). "Friction and Lubrication' chap. 9, p. 107. Methuen, London.

Charnley, J. (1960). Institution of Mechanical Engineers, Proceef ings of Symposium on Biomechanics, April 17, 1959, p. 12. Edwards, F. J. (1960). Institution of Mechanical Engineers, Synt posium on Biomechanics, April 17, 1959. "Derivation of an Expression for Friction Coefficient." Appendix III, p. 19. Ekholm, R., and Norbäck, B. (1951). Acta orthop. scand., 21, 81 . Jones, E. S. (1934). Lancet, 1, 1426.

(1936). Ibid., 1, 1043.

MacConaill, M. A. (1932). J. Anat. (Lond.), 66, 210.

Ogston, A. G., and Stanier, J. E. (1953). Engineer, 135, 678.

Ogston, A. G., and Stanier, .. E. (1953). Engineer, 135, 678 . R. B., and Bauer, W. (1947). Acta med. scand., Suppl. 196, p. 700 .

Stanton, T. E. (1923). Engineer, 135, 678.

Tanner, R. I. (1960). Institution of Mechanical Engineers, Sym- oิ posium on Biomechanics, April 17, 1959. "Calculation of the Shear Rate in the Hip Joint Lubricant," Appendix IV, O p. 21. (1917). J. Anat. (Lond.), 51, Proc. anat. Soc., p. 11. Walmsley, T. (1917). J. Anat. (Lond.)
- (1928). J. Bone Jt Surg., 10, 40.

Discussion.-Prof. E. G. L. Bywaters (Taplow) wondered if Mr. Charnley had considered whether the 을 hyaluronic acid protein complex could in some way $\supset$ modify the individual cartilage surfaces. For example, had he tried wiping the cartilage free of synovial fluid, or substituting serum for synovial fluid in the experi- $N$ mental preparation.

Mr. Charnley replied that he had found it impossible స్ట to wipe the cartilage completely dry-there was always 0 a little more expressed from the cartilage at the point of pressure, for it seemed that normal cartilage, which was very resilient, could absorb synovial fluid in some way. Wiping the joint did not affect its coefficient of friction. In these circumstances there would be little point in $\frac{T}{T}$ testing other substances such as serum as "lubricants". 
DR. C. R. L'Estrange OrMe (Parkstone, Dorset) wondered if enough attention had been paid to the artificial conditions of the experiment, for example the exposure to drying, and the absence of blood supply.

Mr. Charnley reminded the speaker that the cartilage had no circulation, at least not in the form of a red blood supply. The joints used in these experiments had been kept refrigerated until required, and the observations had been made soon after opening. There had been no noticeable drying off.

DR. J. BALl (Manchester) asked whether the high coefficient of lubrication was a function of the whole depth of the cartilage or of the surface layer only.

Mr. Charnley replied that the former was probably true.

DR. H. F. WEST (Sheffield) said that he had tried some silicones as lubricants in joints but they had lost their lubricating properties when mixed with synovial fluid. He had also tried pure graphite-this had disappeared through phagocytosis. Subsequently (1951) he had tried ground-up polytetrafluoro-ethylene (P.T.F.E.)-it had a rather spicular appearance-in rats, but he had given this up because lesions developed that looked sarcomatous.

Mr. Charnley thought that there would be no engineering equivalent to the use of a powder in this way for lubricating a joint. During $2 \frac{1}{2}$ years' experience of its use in surgery, one or two prostheses had been taken out because of mechanical defects. Polytetrafluorethylene was the most inert plastic known, and there had been no evidence of changes in the tissue to cause alarm.

\section{Lubrification des articulations animales}

\section{RÉSUMÉ}

On présente une revue critique des travaux publiés sur la nature de la lubrification des articulations animales. Certaines expériences, servant d'appui à la thérie hydrodynamique, furent répétées. La lubrification des articulations animales est presque certainement un phénomène "limitrophe" (boundary lubrication, Bowden and Tabor, 1956) impliquant une affinité chimique entre le lubrifiant et les surfaces glissantes. On souligne le fait que le coëfficient de friction atteint dans les articulations animales des chiffres étonnamment bas et que ces articlations surpassent en facilité de glissement toutes les combinaisons de surfaces de glissement connues en mécanique. On en déduit que toutes les tentatives de créer des articulations artificielles à base de la thécrie hydrodynamique de lubrification sont vouées à l'échec.

\section{Lubricación en las articulaciones animales Sumario}

Este artículo es una revista crítica de los trabajos publicados sobre la naturaleza de la lubricación en las articulaciones animales. Ciertos experimentos, que son aceptados en sostén de la teoría hidrodinámica fueron repetidos. La lubricación en las articulaciones animales es casi con certeza un fenómeno "limítrofe" (boundary lubrication, Bowden and Tabor, 1956), implicando una afinidad química entre el lubrificante y las superficies deslizantes. Se resalta que el coeficiente de fricción alcanza en las articulaciones animales una cifra asombrosamente baja y que las articulaciones sobrepasan en facilidad de deslizamiento todas las combinaciones de superficies deslizantes conocidas en mecánica. Se deduce que todos los intentos de reproducir articulaciones artificiales a base de la teoría de la lubricación hidrodinámica están condenados al fracaso. 